\title{
Hepatite C: prevalência e fatores de risco entre portadores do VIH/SIDA em Belém, Pará, na Amazônia brasileira
}

\author{
Hepatitis C: prevalence and risk factors among patients with \\ HIV/AIDS in Belém Pará, in Brazilian Amazon
}

\author{
Maria Rita de Cassia Costa Monteiro ${ }^{1}$, Margarida Maria Passeri do Nascimento ${ }^{2}$, \\ Afonso Dinis Costa Passos ${ }^{3}$ e José Fernando de Castro Figueiredo ${ }^{2}$
}

\begin{abstract}
RESUM0
Este trabalho objetivou investigar a prevalência de infecção pelo vírus da hepatite $\mathrm{C}$ e identificar possíveis fatores de risco para sua transmissão, em 406 indivíduos portadores do vírus da imunodeficiência humana, maiores de dezoito anos de idade, atendidos na rede pública de saúde da cidade de Belém, Pará, situada na Amazônia brasileira. Os exames referentes ao anti-VHC foram realizados pelo método de ELSA e a pesquisa do VHC RNA através da reação de polimerase em cadeia. A prevalência de infecção, atual ou pregressa, pelo vírus da hepatite C foi de 16\% (IC: 12,4 - 19,6). A análise multivariada mostrou associação do vírus $\mathrm{C}$ com as variáveis idade, cujo risco significante recaiu no grupo com cinqüenta ou mais anos $(\mathrm{OR}=9,75)$, antecedente de transfusão de sangue $(\mathrm{OR}=4,74)$ e uso de droga ilícita injetável $(\mathrm{OR}=149,28)$. A prevalência do vírus da hepatite C entre os usuários de drogas injetáveis foi de $83,7 \%$ e de $22,1 \%$ na população de transfundidos. Estes resultados indicam a efetiva transmissão do vírus $C$ através da exposição percutânea e reafirmam o grande potencial de risco para hepatite $\mathrm{C}$ contido no uso injetável de drogas ilícitas.
\end{abstract}

Palavras-chaves: Hepatite C. Epidemiologia. VIH/SIDA. Fatores de risco. Amazônia brasileira.

\begin{abstract}
The objective of this investigation was to study the prevalence of hepatitis $C$ virus infection and to identify possible risk factors for its transmission, in 406 adult patients with HIV/AIDS who attended at public health services, in Belém city, Pará, Brazil. The anti-HCV was performed by third generation immunoenzymatic technique, and the HCV RNA by polymerase chain reaction. The overall prevalence of hepatitis C virus was $16 \%$ (CI: 12.4 - 19.6). Multivariate analysis showed association between virus $\mathrm{C}$ infection and age, with significant risk in the group about fifty years old or more $(\mathrm{OR}=9.75)$, blood transfusion ( $\mathrm{OR}=4.74)$ and use of injecting drugs ( $\mathrm{OR}=149.28)$. The hepatitis $\mathrm{C}$ virus infection was detected in $83.7 \%$ of intravenous drug users and $22.1 \%$ of transfused patients. These data indicate the efficient transmission of the virus through the percutaneous exposition and reaffirm the high risk to hepatitis $\mathrm{C}$ among injectable illicit drug user.
\end{abstract}

Key-words: Hepatitis C. Epidemiology. HIV/AIDS. Risk factors. Brazilian amazon.

Indivíduos portadores do vírus da imunodeficiência humana ( VIH) estão freqüentemente co-infectados com outros vírus, incluindo-se os das hepatites. A possibilidade de associação do $\mathrm{VHH}$ com 0 vírus da hepatite $\mathrm{C}$ (VHC) em um mesmo indivíduo está facilitada, uma vez que apresentam vias de contágio semelhantes. Assim, grande número de situações consideradas de risco são comuns a ambos. Alguns trabalhos sugerem a ocorrência de interações biológicas entre esses vírus, na presença de co-infecção determinando, assim, alterações no curso clínico e mesmo no processo de transmissão dessas infecções. № entanto, 0 tema ainda é controverso, necessitando de mais estudos para que se possa obter conclusões mais definitivas.

1. Departamento de Patologia Tropical do Curso de Medicina do Centro de Ciências da Saúde da Universidade Federal do Pará, Belém, PA, Brasil. 2. Divisão de Moléstias Infecciosas e Tropicais do Departamento de Clínica Médica da Faculdade de Medicina de Ribeirão Preto, Universidade de São Paulo, SP, Brasil. 3. Departamento de Medicina Social da Faculdade de Medicina de Ribeirão Preto, Universidade de São Paulo, SP, Brasil.

Endereço para correspondência: Dra. Maria Rita de Cassia Costa Monteiro. Rua São Miguel 560/901, 66033-010 Belém, PA, Brasil,

Fax: 91 252-4136,

e-mail marita@ufpa.br 
A análise das seqüências genômicas do vírus $\mathrm{C}$, clonado em $1989^{12}$, permitiu sua caracterização em seis genótipos e inúmeros subtipos, podendo surgir outras variações, as quasiespecies, que emergem em conseqüência de sua replicação imperfeita. Essa variabilidade genômica facilita seu escape da resposta imune do hospedeiro e parece estar implicada na tendência que tem 0 vírus em induzir infecção crônica².

$0 \mathrm{VHC}$ dissemina-se preferencialmente pelo contato direto com 0 sangue humano, 0 que torna a via parenteral sua principal rota de transmissão $0^{42}$. 0 contágio por via sexual pode ocorrer, embora de forma menos eficaz ${ }^{28}$. Aproximadamente 80\% dos novos infectados evoluem para a cronicidade ${ }^{37}$, com manifestações de cirrose hepática em $10 \%$ a $20 \%$ dos portadores, após um período de 10 a 20 anos de infecção. Esta evolução contribui para que, nos países industrializados, cerca de 30\% dos transplantes de fígado sejam conseqüência da doença hepática por ele ocasionada ${ }^{21}$.

Na atualidade, a infecção pelo VHCé um problema de saúde pública em todos os continentes. Embora os dados conhecidos dos vários países possam não ser os mais fidedignos, a Organização Mundial de Saúde (OMS) estima que cerca de 170 milhões de pessoas estão por ele infectadas, que corresponde a 3\% da população mundial. Prevalências mais elevadas são vistas em alguns países da África, no Mediterrâneo oriental, sudeste da Ásia e Pacífico ocidental. Na Europa e Américas as freqüências são menores ${ }^{43}$. Possivelmente, em conseqüência da pouca eficácia da transmissão perinatal do VHC, sua prevalência em crianças é bem menor quando comparada a dos adultos ${ }^{1}$.

Na presença da co-infecção VHC/VIH, é possível que a deficiência imune ocasionada pelo VIH possa contribuir para alterar a história natural da infecção crônica pelo VHC. A elevação de sua viremia, observada nesta situação $0^{14}$, pode ser um elemento a modificar essa evolução, assim como pode contribuir para 0 aumento do risco de sua transmissão vertical e sexual ${ }^{264}$.

Alguns estudos têm documentado freqüência mais elevada de transmissão entre indivíduos com múltipla parceria sexual, ou quando 0 contato sexual se faz com indivíduos que apresentam a co-infecção $\mathrm{VHC} / \mathrm{VIH}^{4} 22$ 40. Pesquisas mais recentes também mostram aumento nas taxas de transmissão vertical quando as mães estão co-infectadas VHC/VIH ${ }^{2644}$.

A crescente constatação de que a associação entre essas viroses é um fato presente no cotidiano da população portadora do VIH/sida, inclusive com graves repercussões clínicas para o portador, justificam o empenho em conhecer melhor a distribuição da co-infecção VHC/VIH, e os fatores de risco envolvidos nessa transmissão. Neste trabalho são apresentados os resultados obtidos através de um inquérito soroepidemiológico realizado entre indivíduos portadores do VIH/sida, atendidos na rede pública de saúde de Belém, Pará, cidade situada na Amazônia brasileira, cujo objetivo foi determinar a prevalência de infecção atual ou pregressa pelo VHC nessa população, além de identificar os possíveis fatores de risco associados com essa infecção.

\section{CASUÍSTICA E MÉTODOS}

Na presente investigação foi definida como população de referência todos os usuários maiores de 18 anos, portadores do VIH/SIDA, atendidos na Unidade de Referência de Doenças Infecciosas e Parasitárias Especiais e no Hospital Universitário João de Barros Barreto, serviços para os quais drena a quase totalidade desses doentes quando atendidos na rede pública de saúde do município de Belém, Pará. Uma amostra representativa dessa população, atendida no período de setembro de 1999 a abril de 2000, constituiu-se na população de estudo. 0 tamanho amostral foi definido com base na fórmula utilizada para cálculo do $\mathrm{n}$ em levantamentos: $n=z^{2} p q / d^{2}{ }^{6}$. Estabelecendo-se um alfa de 0,05, uma precisão de $5 \%$ e uma prevalência estimada do VHCde $50 \%$, 0 tamanho amostral mínimo foi de 384 indivíduos. Ao final, a amostra constituiu-se de 406 participantes, com todos consentindo na sua participação por escrito. As informações necessárias e 0 convite para inclusão no estudo foram repassadas aos usuários por um dos autores. Todos os dados referentes as caracterísiticas socioeconômicas, demográficas e aos fatores de risco associados à infecção pelo VHC, foram obtidos por meio de entrevista individual, utilizando-se um questionário padronizado.

De cada participante fez-se a coleta de $10 \mathrm{ml}$ de sangue para pesquisa dos marcadores virais. Investigou-se 0 anti-VHC (anticorpo contra 0 vírus da hepatite C) em toda a população de estudo e naqueles com resultado positivo a este marcador, cujo cutoff ficou abaixo de 2,0 ou com resultado duvidoso, realizou-se a pesquisa do VHC-RNA viral. Para detecção do antiVHC utilizou-se reativo fabricado pela United Biomedical Inc. ( UBI ${ }^{\circledR}$ HCV EIA 4.0), e para 0 VHC-RNA usou-se 0 AMPLCOR ${ }^{\circledR}$, fabricado pela Roche Diagnostics. Todos os exames foram realizados no Laboratório de Sorologia do Hospital das Clínicas da Faculdade de Medicina de Ribeirão Preto, seguindo os procedimentos técnicos especificados pelos fabricantes dos reagentes e dos aparelhos empregados. Considerou-se positivo para $0 \mathrm{VHC}$ todo soro com resultado reagente a um ou outro marcador pesquisado, anti-VHC ou VHC-RNA, respectivamente.

0 projeto desta pesquisa foi aprovado pelo Comitê de Ética em Pesquisa do Hospital das Clínicas da Faculdade de Medicina de Ribeirão Preto da Universidade de São Paulo e pela Secretaria Executiva de Estado de Saúde Pública do Pará.

Os dados desta investigação foram analisados nos programas EPI-INFO 6.04b e SAS. As informações foram inicialmente submetidas a uma análise univariada, testandose a existência de associação entre possíveis variáveis independentes (fatores de risco) e a presença de infecção. Nesta etapa utilizou-se os testes qui-quadrado, qui-quadrado para tendência e teste exato de Fisher. As variáveis com valor de $\mathrm{p} \leq 0,25{ }^{29}$ foram incluídas em um modelo de regressão logística não condicional, tendo sido previamente testadas para a ocorrência de interação. Em todas as situações, 0 limite adotado de significância estatística foi de 0,05. Para introdução no modelo multivariado, das variáveis que permitiram a resposta 
ignorado, foram considerados somente os resultados da análise univariada obtidos após a exclusão desses casos (ignorados).

\section{RESULTADOS}

Os resultados apresentados neste trabalho fazem parte de uma investigação mais ampla, realizada entre os portadores do $\mathrm{VIH} /$ sida da cidade de Belém, Pará, Brasil, com o propósito de investigar a epidemiologia das hepatites A, B e C no referido grupo. Desse modo, mais dados relativos a esta população foram obtidos, os quais estão divulgados em outras publicações.

A população investigada apresentou uma média de idade de 34,2 anos, com desvio padrão de 8,26 e mediana de 33,5 anos. A distribuição dos resultados do $\mathrm{VHC}$ de acordo com a faixa etária e sexo está demonstrada na Tabela 1. Apresentaram-se positivos a pelo menos um marcador 65 pacientes, determinando uma prevalência global de infecção pelo vírus $C$ de $16 \%$ (IC: 12,4 - 19,5). No sexo masculino, a frequêencia de infecção foi de $17,3 \%$ e $12,4 \%$ no feminino ( $\chi^{2}$ Yates corrigido $=1,05$; $\mathrm{p}=0,306)$. Com relação a idade, a menor e a maior freqüência de infecção situaram-se nas faixas etárias mais jovem e mais idosa, respectivamente $\left(\chi^{2}\right.$ para tendência linear $\left.=2,43 ; p=0,119\right)$.

Tabela 1 - Distribuição do VHC+ de acordo com sexo e faixa etária.

\begin{tabular}{|c|c|c|c|c|c|c|c|c|c|}
\hline \multirow[b]{4}{*}{ Idade } & \multicolumn{9}{|c|}{ VHC } \\
\hline & \multicolumn{6}{|c|}{ Sexo } & & & \\
\hline & \multicolumn{3}{|c|}{ masculino } & \multicolumn{3}{|c|}{ feminino } & \multicolumn{3}{|c|}{ total } \\
\hline & $\mathrm{n}^{0}$ & + & $\%$ & $n^{0}$ & + & $\%$ & $\mathrm{n}^{0}$ & + & $\%$ \\
\hline$\overline{18|-| 29}$ & 90 & 10 & 11,1 & 39 & 5 & 12,8 & 129 & 15 & 11,6 \\
\hline $30|-| 39$ & 145 & 29 & 20,0 & 46 & 5 & 10,8 & 191 & 34 & 17,8 \\
\hline $40|-| 49$ & 50 & 8 & 16,0 & 15 & 3 & 20,0 & 65 & 11 & 16,9 \\
\hline$\geq 50$ & 16 & 5 & 31,3 & 5 & 0 & 0,0 & 21 & 5 & 23,8 \\
\hline Total & 301 & 52 & 17,3 & 105 & 13 & 12,4 & 406 & 65 & $16,0^{*}$ \\
\hline
\end{tabular}

$\mathrm{n}^{0}=$ número de indivíduos pesquisados. $+=$ indivíduos com um ou mais resultados positivos ao VHC. \% = prevalência. ${ }^{*}$ = prevalência global.

0 uso de droga ilícita não injetável foi referido por 38,6\% (157/406) da população investigada e a taxa de infecção pelo vírus C neste grupo foi de 27,4\% ( $\chi^{2}$ Yates corrigido $=23,29$; $\mathrm{p}=0,000)$. Afirmaram utilizar droga ilícita injetável 10,6\% (43/406) dos participantes e a prevalência observada no grupo usuário foi de 83,7\% e de 8\% entre os não usuários ( $\chi^{2}$ Yates corrigido $=158,40 ; p=0,000$ ) (Figura 1$)$.

A taxa de infecção pelo VHCno grupo que referiu antecedente de transfusão de sangue e/ou hemoderivados foi de 22,1\% (Tabela 2). Na análise univariada, ao excluir a categoria ignorado, obteve-se resultado próximo ao limite de significância adotado nesta pesquisa: $\chi^{2}$ Yates corrigido $=3,32 ; p=0,068$.

Considerando a preferência sexual da população de estudo, 44,6\% (181/406) dos participantes referiram comportamento heterossexual, 40,4\% (164/406) bissexual e 14,8\% (60/406) homossexual. As taxas de infecção pelo VHC nestes grupos foram, respectivamente, 18,8\%, 12,8\% e $15,0 \%\left(\chi^{2}=2,35 ; 2\right.$ GL; $\left.p=0,309\right)$.

Estão descritas na Tabela 3 as prevalências do VHC de acordo com os fatores de risco investigados, que apresentaram resultados significantes na análise univariada.

Houve risco diferenciado de infecção na presença de tatuagem. A prevalência do VHC no grupo tatuado foi de $30 \%$ ( $\chi^{2}$ Yates corrigido $=17,96 ; p=0,000)$. Informaram já ter realizado acupuntura somente nove participantes e a taxa de infecção neste grupo foi de $44,4 \%$, três vezes superior a observada nos que negaram este antecedente ( teste exato de Fisher: $\mathrm{p}=0,040$ ).

Os participantes com história de pequena cirurgia apresentaram risco significante de infecção na análise

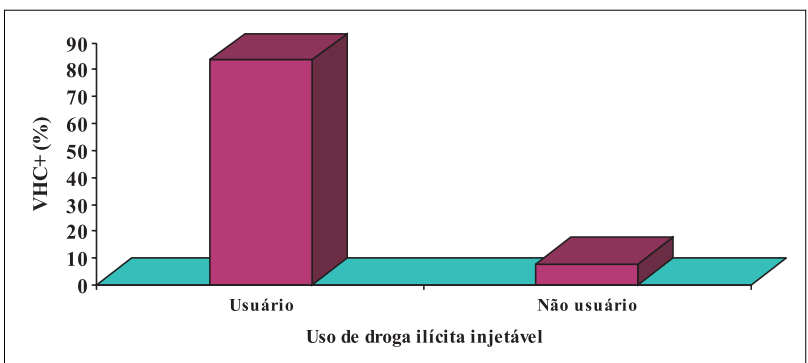

Figura 1 - Distribuição do VHC+ de acordo com o uso de droga ilícita injetável.

Tabela 2 - Distribuição da prevalência global deinfecção pelo VHC segundo antecedente de transfusão de sangue.

\begin{tabular}{|c|c|c|c|c|c|c|}
\hline \multirow{3}{*}{ Transfusão de sangue } & \multicolumn{6}{|c|}{$\mathrm{VHC}$} \\
\hline & \multicolumn{2}{|c|}{ positivo } & \multicolumn{2}{|c|}{ negativo } & \multicolumn{2}{|c|}{ total } \\
\hline & $\mathrm{n}^{0}$ & $\%$ & $\mathrm{n}^{0}$ & $\%$ & $\mathrm{n}^{0}$ & $\%$ \\
\hline Sim & 23 & 22,1 & 81 & 77,9 & 104 & 100,0 \\
\hline Nã̃o & 41 & 13,9 & 255 & 86,1 & 296 & 100,0 \\
\hline Ignorado & 1 & 16,7 & 5 & 83,3 & 6 & 100,0 \\
\hline Total & 65 & 16,0 & 341 & 84,0 & 406 & 100,0 \\
\hline
\end{tabular}

Tabela 3 - Fatores de risco e distribuição da prevalência do virus da hepatite C.

\begin{tabular}{|c|c|c|c|c|c|c|c|c|}
\hline \multirow{4}{*}{ Fator de risco } & \multicolumn{8}{|c|}{ VHC } \\
\hline & \multicolumn{4}{|c|}{ fator de risco presente } & \multicolumn{4}{|c|}{ fator de risco ausente } \\
\hline & \multicolumn{2}{|c|}{ positivo } & \multicolumn{2}{|c|}{ negativo } & \multicolumn{2}{|c|}{ positivo } & \multicolumn{2}{|c|}{ negativo } \\
\hline & $\mathrm{n}^{0}$ & $\%$ & $\mathrm{n}^{0}$ & $\%$ & $\mathrm{n}^{0}$ & $\%$ & $\mathrm{n}^{0}$ & $\%$ \\
\hline Tatuagem & 30 & 30,0 & 70 & 70,0 & 35 & 11,4 & 271 & 88,6 \\
\hline Acupuntura & 4 & 44,4 & 5 & 55,6 & 61 & 15,4 & 335 & 84,6 \\
\hline Pequena cirurgia & 53 & 18,4 & 235 & 81,6 & 10 & 8,8 & 103 & 91,2 \\
\hline Internação em reformatórios ou prisão & 27 & 32,9 & 55 & 67,1 & 36 & 11,2 & 286 & 88,8 \\
\hline Uso de droga ilícita não injetável & 43 & 27,4 & 114 & 72,6 & 22 & 8,8 & 227 & 91,2 \\
\hline Contato sexual com usuário de droga & 44 & 22,8 & 149 & 77,2 & 11 & 8,4 & 120 & 91,6 \\
\hline Contato sexual com prostituta & 32 & 23,2 & 106 & 76,8 & 20 & 12,3 & 143 & 87,7 \\
\hline
\end{tabular}


univariada. Nestes, foi de $18,4 \%$ a proporção de positivos ao $\operatorname{VHC}\left(\chi^{2}\right.$ Yates corrigido $\left.=4,90 ; p=0,026\right)$.

Entre os indivíduos que referiam internação em reformatório ou prisão, a prevalência observada do VHC foi de $32,9 \%$, cerca de três vezes superior a obtida pelos que negaram este antecedente, que foi de $11,2 \%$ ( $\chi^{2}$ Yates corrigid $0=21,86 ; p=0,000)$.

Somente um participante negou experiência sexual, que foi excluído quando se fez a análise das variáveis que investigavam associação de alguns aspectos do comportamento sexual com a infecção pelo VHC. Na população com experiência sexual, a análise univariada detectou risco diferenciado na categoria que confirmou contato sexual com usuário de droga ilícita, cuja prevalência de infecção foi de 22,8\% ( $\chi^{2}$ Yates corrigido $=10,48$; $p=0,001)$. A presença de associação entre $0 \mathrm{VHC}$ e 0 contato sexual com prostituta foi investigada somente na população masculina. A taxa observada no grupo que referiu contato, 23,2\%, foi significante estatisticamente ( $\chi^{2}$ Yates corrigid $0=5,49$; $\mathrm{p}=0,019)$.

Alguns itens relativos a condição socioeconômica da população de estudo foram investigados, tais com renda familiar, posse de domicílio e de alguns bens duráveis ( geladeira, aparelho de televisão a cores, aparelho de som com toca-disco, aparelho de videocassete, linha telefônica fixa ou móvel, freezer, aspirador de pó, forno microondas, lavadora de roupa, computador, automóvel e canal de televisão por assinatura). Embora se tenha encontrado alguns resultados limítrofes, nenhuma associação significante foi observada na análise univariada.

Outras variáveis investigadas e que também não apresentaram resultados significantes nas análises executadas foram: situação conjugal, local de nascimento, região geográfica de nascimento, área de nascimento, tempo de residência em Belém, escolaridade, situação ocupacional, antecedente de icterícia, antecedente de hepatite, contato com caso de hepatite, exposição ocupacional ao sangue, tipo de tratamento dentário já realizado, antecedente de cirurgia, preferência sexual e antecedente de doenças sexualmente transmissíveis.

As variáveis com valor de $\mathrm{p} \leq 0,25$ na análise univariada foram introduzidas em um modelo de regressão logística não condicional. Após o controle dos fatores de confundimento, mantiveram-se independentemente preditivas de infecção pelo VHC, no grupo populacional investigado: idade, na faixa etária de 50 ou mais anos, antecedente de transfusão de sangue, uso de droga ilícita injetável e a posse de freezer (Tabela 4).

Tabela 4 - Resultados da análise do modelo final de regressão logística para $0 \mathrm{VHC}$

\begin{tabular}{lrcr}
\hline $\begin{array}{l}\text { Variável } \\
\text { Idade (anos) }\end{array}$ & Odds Ratio & IC 95\% & $P$ \\
\hline 18 a 29 & & & - \\
30 a 39 & 1,00 & - & 0,120 \\
40 a 49 & 2,20 & $0,81-5,92$ & 0,131 \\
$\geq 50$ anos & 2,52 & $0,75-8,40$ & 0,001 \\
Posse de freezer & 9,75 & $2,42-39,19$ & 0,028 \\
Transfusão de sangue & 2,54 & $1,10-5,86$ & 0,000 \\
Uso de droga ilícita injetável & 4,74 & $2,09-10,73$ & 0,000 \\
\hline
\end{tabular}

Selecionou-se através de sorteio, entre os indivíduos potencialmente mais expostos à infecção pelo VHC - ou seja, os que haviam recebido transfusão de sangue até 1989 e os usuários de drogas injetáveis - um grupo de 13 participantes, cujos soros apresentaram resultados negativos para 0 antiVHC pelo ELISA. Neste grupo, realizou-se a pesquisa do VHC RNA viral pela técnica da PCR, no intuito de observar possíveis discordâncias entre os dois métodos. 0 grupo formado compôs-se de três usuários de drogas ilícitas endovenosas e dez transfundidos. Os resultados da PCR mostraram-se negativos em todas estas amostras, confirmando os resultados obtidos por meio do método de ELISA.

\section{DISCUSSÃ0}

0 vírus da hepatite $\mathrm{C}$, largamente difundido nos vários continentes, tem sua circulação mantida, preferencialmente, através da exposição percutânea. Muito embora, em algumas regiões do mundo, seu controle no sangue transfundido não seja rotina ${ }^{30}$, nos países onde se estabeleceu essa prática, esse modo de transmissão virtualmente inexiste ${ }^{36}$, ficando os usuários de drogas ilícitas injetáveis como os grandes reservatórios do vírus. Cerca de $50 \%$ a $80 \%$ desses usuários tornam-se infectados 6 a 12 meses após iniciar o uso de droga injetável ${ }^{3}$.

Os portadores de infecção pelo VIH, em sua maioria incluídos nos grupos de risco das doenças de transmissão percutânea e sexual, apresentam taxas de infecção pelo VHC habitualmente mais elevadas que a população geral, as quais variam na dependência dos comportamentos presentes, com valores menores quando predomina 0 risco sexual e bem mais elevados nos grupos com exposição parenteral ${ }^{1016} 1739$.

Na amostra em estudo, a prevalência global de infecção pelo VHC foi de $16 \%$, valor mais próximo daqueles observados entre portadores do $\mathrm{VIH}$, cujo principal fator de risco para sua transmissão é sexual ${ }^{1923} 3134$.

Habitualmente, a infecção pelo VHC começa a tornar-se mais prevalente na adolescência e idade adulta, uma vez que, nesse período, os fatores de risco de importância epidemiológica estão mais presentes. Assim, é freqüente 0 encontro de taxas de infecção crescentes com a idade ${ }^{18} 24$, fato observado na população aqui estudada (Tabela 1). Contudo, apesar do crescimento proporcional à idade, apenas a faixa com $50 \mathrm{ou}$ mais anos apresentou risco diferenciado de infecção, cuja ocorrência de hepatite Cfoi quase dez vezes superior à observada na faixa etária mais jovem. Este achado sugere que a infecção no grupo ocorreu em períodos remotos, provavelmente por transfusão de sangue, ou mesmo pelo uso de drogas (Tabela 4) .

0 uso de drogas ilícitas injetáveis tem sido o fator de risco mais freqüentemente implicado na transmissão do vírus da hepatite $\mathrm{C}^{51518203242}$. Assim, a maior parcela de infectados pelo VHC é composta destes usuários, muito embora 0 uso de droga por outras vias possa estar associado à infecção ${ }^{13}$. Mesmo em grupos de homens que fazem sexo com homens, nos quais práticas sexuais de alto risco estão presentes com 
alguma frequiência, ainda assim, a utilização de drogas injetáveis é fator significante para circulação do vírus nessa população ${ }^{8}$. Nesta pesquisa, embora tenha ocorrido associação significante entre 0 VHC e 0 uso de droga ilícita não injetável na análise univariada, esta não se manteve quando a variável foi introduzida no modelo de regressão logística. Entretanto, 0 uso de droga injetável, à semelhança dos múltiplos trabalhos já citados, mostrouse como fator de risco independentemente preditivo de infecção (Figura 1 e Tabela 4), reafirmando o grande potencial de risco para hepatite $C$ contido no uso injetável de drogas ilícitas.

A triagem das infecções de transmissão sanguínea ainda não é a norma dos bancos de sangue em muitos países. Até 0 ano de 1997, entre 12 países da América Latina, apenas seis possuíam cobertura $100 \%$ eficaz no controle do $\mathrm{VHC}^{35}$. No Brasil, há um controle efetivo nos bancos de sangue do setor público, todavia, não se tem conhecimento de nenhuma publicação oficial com os dados nacionais sobre as doações de sangue no setor privado.

Nos EUA, com a introdução da pesquisa do anti-VHC nos pré-doadores, no início dos anos noventa do século $X^{41}$, a hepatite $C$ pós-transfusional tornou-se um evento virtualmente raro. Contudo, mesmo nos locais onde a triagem dos doadores é universal, ainda assim é possível a transmissão de infecções virais nas doações que se fazem durante 0 período de janela imunológica, quando os anticorpos ainda não estão detectáveis ${ }^{36}$. Estudos populacionais em várias regiões têm identificado a transfusão de sangue, especialmente se realizada até 0 início da década de noventa, como um fator de risco freqüentemente associado à infecção pelo VHC ${ }^{1820}$.

Entre portadores do VIH, estudos têm demonstrado associação entre infecção pelo $\mathrm{VHC}$ e transfusão de sangue ${ }^{10} 17$, resultados que coincidem com os observados na amostra populacional aqui investigada, em quea transfusão de sangue mostrou-se como fator de risco independentemente preditivo de infecção pelo VHC ( Tabelas 2 e 4), na análise por regressão logística.

Também podem ser fonte de infecção as tatuagens, freqüentes na atualidade, inclusive as cosméticas ${ }^{151838}$, assim como algumas práticas de medicina alternativa ${ }^{25}$, embora à acupuntura não tenha sido atribuído risco maior de infecçãa ${ }^{15}{ }^{18}$. Certamente, a negligência na aplicação das regras básicas para controle de infecções, seja 0 grande fator a contribuir para manter a transmissão desses vírus por meio desses procedimentos. Na presente amostra, os grupos com antecedentes de tatuagem $\mathrm{e}$ pequena cirurgia apresentaram riscos diferenciados de infecção na análise univariada, mas que desapareceram quando introduzidos no modelo de regressão logística. 0 antecedente de acupuntura também surgiu como fator de risco significante na análise univariada, entretanto, a pequena amostra submetida ao procedimento deixa este resultado com reduzida confiabilidade. De todo modo, na análise multivariada esta significância não foi mantida.

No Brasil, as precárias condições físicas e assistenciais observadas em uma grande maioria das instituições que abrigam indivíduos em cumprimento de algum tipo de pena, sejam elas para adultos ou menores infratores, deixam esses indivíduos sujeitos ao adoecimento mais freqüente, particularmente por doenças de natureza infectocontagiosa, assumindo especial importância as de transmissão sexual e parenteral ${ }^{11}{ }^{33}$. Nesta pesquisa, investigou-se a presença de associação entre a infecção pelo $\mathrm{VHCe} 0$ antecedente de internação em prisão ou reformatório, uma vez que a presença do vírus tem sido expressiva nessa populaçãa ${ }^{9} 152732$. Embora tenha havido resultado significante na análise univariada (Tabela 3), este não se manteve no modelo multivariado.

Muito embora esteja documentada em vários trabalhos, considera-se de menor expressão epidemiológica a transmissão sexual do $\mathrm{VHC}^{8}{ }^{40}$, se comparada aos vírus da hepatite B e da imunodeficiência humana. Entretanto, sob determinadas condições, esse modo de transmissão pode assumir importância mais expressiva. Na co-infecção VHC/VIH parece ocorrer uma interação entre os vírus, com aumento da carga viral do VHC, favorecendo, sobremaneira, sua transmissão sexual ${ }^{22}$. Determinadas práticas sexuais, se exercidas promiscuamente, principalmente quando envolvem sexo anal e/ou parceria sexual múltipla, são condições que facilitam 0 contági $0^{40}$, especialmente se os parceiros pertencem a grupos de risco. Vários trabalhos identificam, como fator de risco independente, a atividade sexual com parceiro usuário de droga ilícita injetáve ${ }^{1532}$.

Embora tenha sido detectada prevalência ligeiramente mais elevada entre os heterossexuais, a opção sexual da população aqui investigada não se mostrou como fator de risco independente para a infecção. 0 contato sexual com usuário de qualquer tipo de droga ilícita mostrou-se associado à infecção pelo VHC somente na análise univariada (Tabela 3).

0 contato sexual com prostituta, a despeito da reduzida transmissão sexual do VHC, pode ser um fator de risco para a infecção $0^{18}$. Na investigação desta variável, na população masculina, a análise multivariada não apresentou resultado significante.

A renda familiar, a posse de imóvel e de alguns bens de consumo duráveis, também não mostraram associação significante com o VHC. Como a posse de freezer apresentou valor marginal na análise univarida, ele foi incluído no modelo de regressão logística, cujo resultado final evidenciou associação, de forma independente, entre a posse deste bem e a infecção pelo VHC. No entanto, entende-se que esta associação, de forma isolada, pouco representa na avaliação geral das condições socioeconômicas do grupo investigado. Vale ressaltar que, durante a coleta de dados, vários participantes que informaram trabalhar por conta própria, eram donos de negócios instalados em suas próprias residências, vendendo produtos que necessitam de freezer para conservação, tornando este, mais que um bem de consumo familiar, um instrumento de trabalho. Năo obstante a possibilidade de aplicação de outros métodos para avaliação da condição socioeconômica, os aqui empregados, de modo geral, não detectaram existência efetiva de associação entre a condição socioeconômica e a frequiência de infecção pelo VHC na população investigada.

É possível que a imunossupressão relacionada ao VIH possa determinar redução na produção de anticorpos para o VHC, na presença de co-infecçã $0^{14}$, fato que pode interferir nos resultados dos exames utilizados para sua detecção. Contudo, os testes ELISA 
de segunda e terceira geração, estes últimos os empregados nesta pesquisa, têm demonstrado eficácia na detecção do anti-VHC em diversas amostras populacionais, inclusive em grupos de imunodeprimidos ${ }^{73}$. Quando se fez a pesquisa do VHC RNA viral pelo método da PCR, em um subgrupo desta amostra com resultado do anti-VHC negativo e cujo fator de risco referido havia sido a exposição parenteral (usuários de drogas ilícitas injetáveis e transfundidos), os resultados deste marcador mostraram-se concordantes em $100 \%$ dos casos com os encontrados pelo método de ELSA, ou seja, todos negativos. A semelhança dos resultados aqui encontrados, de certo modo, pode ser a tradução da eficácia do teste imunoenzimático utilizado nesta pesquisa.

Os resultados encontrados no presente estudo mostram significante transmissão do VHC por meio da exposição percutânea, uma vez que, os fatores de risco independentemente preditivos de infecção foram o uso de drogas ilícitas injetáveis e a transfusão de sangue. Nenhuma das variáveis referentes a atividade sexual mostraram risco diferenciado de infecção. Também não se observou, de forma consistente, associação entre a infecção e os aspectos investigados, relacionados à condição socioeconômica da população.

Foi expressiva a freqüência do VHC nesta população. Com 0 prolongamento na sobrevida dos portadores do $\mathrm{VIH}$ e a possibilidade freqüente de cronificação da infecção pelo VHC, esta vem se tornando um importante problema clínico entre os portadores do VIH/SIDA.

\section{REFERÊNCIAS BIBLIOGRÁFICAS}

1. Al-Faleh FZ, Ayoola EA, Al-Jeffry M, Al-Rashed R, Al-Mofarreh M, Arif M, Ramia S, Al-Karawi M, Al-Shabrawy M. Prevalence of antibody to hepatitis Cvirus among saudi arabian children: a community-based study. Hepatology 14:215-218, 1991

2. Alter HJ, Seef LB. Recovery, persistence, and sequelae in hepatitis $C$ infection: a perspective on long-term outcome. Seminars in Liver Disease 20:17-35, 2000

3. Alter MJ. Epidemiology of hepatitis C. Hepatology 26 ( supl 1):62S-65S, 1997.

4. Alter MJ, Kruszon-Moran D, Nainan OV, McQuillan GM, Gao F, Moyer LA, Kaslow RA, Margolis HS. The prevalence of hepatitis $C$ virus infection in the United States, 1988 through 1994. New England Journal of Medicine 341:556-562, 1999

5. Bellentani S, Pozzato G, Saccoccio G, Crovatto M, Croce LS, Mazzoran L, Masutti F, Cristianini G, Tiribeli C. Clinical course and risk factors of hepatitis $\mathrm{C}$ virus related liver disease in the general population: report from the Dionysos study. Gut 44:874-880, 1999.

6. Berquó ES, Souza JMP, Gotlieb SLD. Bioestatística. Editora Pedagógica e Universitária, São Paulo, 1981.

7. Bonacini M, Lin HJ, Hollinger B. Effect of coexisting HIV-1 infection on the diagnosis and evaluation of hepatitis $C$ virus. Journal of Acquired Immune Deficiency Syndromes 26:340-344, 2001.

8. Buchbinder SP, Katz MH, Hessol NA, Liu J, O'Malley PM, Alter MJ. Hepatitis $C$ virus infection in sexually active homosexuaal men. Journal of Infection 29:263-269, 1994

9. Burattini MN, Massad E, Rozman M, Azevedo RS, Carvalho HB. Correlation between HIV and HCV in brazilian prisoners: evidence for parenteral transmission inside prison. Revista de Saúde Pública 34:431-436, 2000.

10. Carmo RA, Lima AA, Andrade CA, Oliveira JGF, Oliveira MS, Santi LQ, Bicalho HNC, Silva SMN. Epidemiological study of hepatitis C virus ( HCV)/HIV coinfection in Brazil. In: Resumo of The XIII International AIDS, WeOrA531, 2000.

11. Center for Disease Control and Prevention. Hepatitis B outbreak in a state correctional facility, 2000. Morbidity and Mortality Weekly Report 50:529-532, 2001

12. Choo Q-L, Kuo G, Weiner AJ, Overby LR, Bradley DW, Houghton M. Isolation of a cDNA clone derived from a blood-borne non-A, non-B viral hepatitis genome. Science 244: 359-362, 1989.

13. Conry-Cantilena C, Vanraden M, Giblle J, Melpoder J, Shakil O, Viladomiu L, Cheung L, Di Bisceglie A, Hoofnagle J, Shih JW, Kaslow R, Ness P, Alter HJ. Routes of infection, viremia, and liver disease in blood donors found to have hepatitis $C$ virus infection. New England Journal of Medicine 334:1691-1696, 1996

14. Cribier B, Rey D, Schmitt C, Lang J-M, Kirn A, Stoll-Keller F. High hepatitis $\mathrm{C}$ viraemia and impaired antibody response in patients coinfected with HIV. AIDS 9:1131-1136, 1995.

15. Delage G, Infante-Rivard C, Chiavetta J-A, Willwms B. Risk factors for acquisition of hepatitis $\mathrm{C}$ virus infection in blood donors: results of a casecontrol study. Gastroenterology 116:893-899, 1999.

16. Denis F, Adjide CC, Rogez S, Delpeyroux C, Rogez JPh, Weinbreck P. Séroprévalence des marqueurs des virus des hépatites $B$, C et Dd chez 500 patients infectés par le virus de l' immunodéficience humaine. Pathologie Biologie 45:701-708, 1997.

17. Dimitrakopoulos A, Takou A, Haida A, Molangeli S, Gialeraki A, Kordossis T. The prevalence of hepatitis B and C in HIV-positive Greek patients: relationship to survival of deceased AIDS patients. Journal of Infection 40:127-131, 2000

18. Dominguez A, Bruguera M, Vidal J, Plans P, Salleras SL. Community-based seroepidemiological survey of HCV infection in Catalonia, Spain. Journal of Medical Virology 65:688-693, 2001.

19. Dorrucci M, Pezzotti P, Phillps AN, Lepri AC, Rezza G. Coinfection of hepatitis $C$ virus with human immunodeficiency virus and progression to AIDS. Journal of Infectious Disease 172:1503-1508, 1995.

20. Dubois F, Desenclos J-C, Mariotte N, Goudeau A, Hepatits C in a french population-based survey, 1994: seroprevalence, frequency of viremia, genotype distribuition, and risk factors. Hepatology 25:1490-1496, 1997.

21. European Association for the Study of the Liver (EASL). International Consensus Conference on Hepatitis C. Journal of Hepatology 30:956-961, 1999.

22. Eyster ME, Alter HJ, Aledort LM, Quan S, Hatzakis A, Goedert JJ. Heterosexual co-transmission of hepatitis $\mathrm{C}$ virus ( $\mathrm{HCV}$ ) and human immunodefiency virus (HIV). Annals of Internal Medicine 115:764-768, 1991.

23. Fanboim H, Gonzalez J, Fassio E, Martinez A, Otegui L, Eposto M, Cahn P, Marino R, Landeira G, Suaya G, Gancedo E, Castro R, Brajterman L, Laplume $H$. Prevalence opf hepatitis viruses in an anti-human immunodeficiency virus-positive population from Argentina. A multicentre study. Journal of Viral Hepatitis 6:53-57, 1999.

24. Foccacia R, Conceição OJG , Sette Jr H, Sabino E, BassitaL, Nitrini DR, Lomar AV, Lorenço R, Souza FV de, Kiffer CRV, Santos EB, Gonzalez MP, Sáez-Alquézar A, Riscal JR, Chamaone DF. Estimated prevalence of viral hepatitis in the general population of the municipality of São Paulo, measured by serologic survey of a stratified, randomized and residencebased population. Brazilian Journal of Infectious Diseases 2:269-284, 1998.

25. Gabriel C, Blauhut B, Greul R, Schneeweis B, Roggendorf M. Transmission of hepatitis $\mathrm{C}$ by ozone enrichment of autologous blood. Lancet 347:541, 1996.

26. Gibb DM, Goodall RL, Dunn DT, Healy M, Neave P, Cafferkey M, Butler K. Mother-to-child transmission of hepatitis $\mathrm{C}$ virus: evidence for preventable peripartum transmission. Lancet 356:904-907, 2000.

27. Guimarães T, Granato CFH, Varella D, Ferraz MLG, Castelo A, Kallas EG. High prevalence of hepatitis $\mathrm{C}$ infection in a brazilian prison: identification of risk factors for infection. Brazilian Journal of Infectious Diseases 5:111118, 2001.

28. Halfon P, Riflet H, Renou C, Quentin Y, Cacoub P. Molecular evidence of male-to-female sexual transmission of hepatitis $C$ virus after vaginal and anal intercourse. Journal of Clinical Microbiology 39:1204-1206, 2001. 
29. Hosmer Jr DW, Stanley L. Applied logistic regression. John Wiley \& Sons, New York, 1989.

30. Maida MJ, Daly CC, Hoffman I, Cohen MS, Kumwenda M, Vernazza PL. Prevalence of hepatitis $\mathrm{C}$ infection in Malawi and lack of association with sexually transmitted diseases. European Journal of Epidemiology 16:11831184, 2000.

31. Mendel I, Clotteau L, Lambert S, Buffet-Janvresse C. Hepatitis C virus infection in an HIV-positive population in Normandy: antibodies, HCV RNA and genotype prevalence. Journal of Medical Virology 47:231-236, 1995.

32. Murphy EL, Bryzman SM, Glynn SA, Ameti DI, Thomson RA, Williams AE, Nass CC, Ownby HE, Schreiber GB, Kong F, Neal KR, Nemo GJ. Risk factors for hepatitis $\mathrm{C}$ virus infection in United States blood donors. NHLBI retrovirus epidemiology donor study (REDS). Hepatology 31:756-762, 2000.

33. Osti NM. Determinação do perfil sorológico para marcadores de hepatite $\mathrm{B}$ e C em amostras de soro positivas e negativas para anticorpos anti-HIV entre presidiários da região de Campinas- SP, 1997. Tese de doutorado, Instituto de Biologia, Universidade Estadual de Campinas, Campinas, SP, 1999.

34. Saillour F, Dabis F, Dupon M, Lacoste D, Trimoulet P, Rispal P, Monlun E, Ragnaud J-M, Morlat P, Pellegrin J-L, Fleury H, Couzigou P. Prevalence and determinants of antibodies to hepatitis $\mathrm{C}$ virus and markers for hepatitis $\mathrm{B}$ virus infection in patients with HIV infection in Aquitaine. British Medical Journal 313:461-464, 1996.

35. Schmunis GA, Zickker F, Cruz JR, Cuchi P. Safety of blood supply for infectious diseases in Latin American countries, 1994-1997. American Journal of Tropical Medicine and Hygiene 65:924-930, 2001.
36. Schreiber GB, Busch MP, Kleinman SH, Korelitz JJ. The risk of transfusiontransmitted viral infections. New England Journal of Medicine 334:16851690, 1996.

37. Seeff $L B$, Hollinger FB, Alter HJ, Wright EC, Cain CMB, Buskell ZJ, Ishak KG, Iber FL, Toro D, Samanta A, Koretz RL, Perrillo RP and other authors. Long-term mortality and morbidity of transfusion-associated non-A, non$B$ hepatitis and type $C$ hepatitis: a national heart, lung, and blood institute collaborative study. Hepatology 33:455-463, 2001.

38. Sun D-X, Zhang F-G, Geng Y-Q, Xi D-S. Hepatitis C transmission by cosmetic tattooing in women. Lancet 347:541, 1996

39. Thio CL, Nolt KR, Astemborski J, Vlahov D, Nelson KE, Thomas DL. Screening for hepatitis $\mathrm{C}$ virus in human immunodeficiency virus infected individuals. Journal of Clinical Microbiology 38:575-577, 2000.

40. Thomas DL, Zenilman JM, Alter HJ, Shih JW, Galai N, Carella AV, Ouinn TC Sexual transmission of hepatitis $C$ virus among patients attending sexually transmitted diseases clinics in Baltimore-an analysis of 309 partnerships. Journal Infectious Disease 171:768-775, 1995.

41. Tobler LH, Busch MP. History of posttransfusion hepatitis. Clinical Chemistry 43:1487-1493, 1997.

42. Van Beek I, Dwyer R, Dore GJ, Luo K, Kaldor JM. Infection with HIV and hepatitis $\mathrm{C}$ among injecting drug users in a prevention setting: retrospective cohort study. Britsh Medical Journal 317:433-437, 1998.

43. World Health Organization. Hepatitis C - global prevalence (update). Weekly Epidemiological Record 74:421-428, 1999.

44. Zanetti AR, Tanzi E, Romanó L, Zuin G, Minola E, Vecchi L, Principi N. A prospective study on mother-to-infant transmission of hepatitis $\mathrm{C}$ virus. Intervirology 41:208-212, 1998. 